\title{
Malignant Uterine Neoplasm
}

National Cancer Institute

\section{Source}

National Cancer Institute. Malignant Uterine Neoplasm. NCI Thesaurus. Code C3552.

Primary or metastatic malignant neoplasm involving the uterine corpus and/or the cervix. 